$10-8-2018$

\title{
Using Cyclical Components to Improve the Forecasts of the Stock Market and Macroeconomic Variables
}

\author{
Kenneth R. Szulczyk \\ Curtin University Malaysia, ken@ken-szulczyk.com
}

Shibley Sadique

University of Rajshahi, sadique@ru.ac.bd

Follow this and additional works at: https://digitalcommons.wayne.edu/jmasm
Part of the Applied Statistics Commons, Social and Behavioral Sciences Commons, and the Statistical Theory Commons

\section{Recommended Citation}

Szulczyk, Kenneth R. and Sadique, Shibley (2018) "Using Cyclical Components to Improve the Forecasts of the Stock Market and Macroeconomic Variables," Journal of Modern Applied Statistical Methods: Vol. 17 : Iss. 1, Article 25.

DOI: Economic variables such as stock market indices, interest rates, and national output measures contain cyclical components. Forecasting methods excluding these cyclical components yield inaccurate out-of-sample forecasts. Accordingly, a three-stage procedure is developed to estimate a vector autoregression (VAR) with cyclical components. A Monte Carlo simulation shows the procedure estimates the parameters accurately. Subsequently, a VAR with cyclical components improves the root-mean-square error of out-of-sample forecasts by $50 \%$ for a stock market model with macroeconomic variables.

Available at: https://digitalcommons.wayne.edu/jmasm/vol17/iss1/25 


\section{Using Cyclical Components to Improve the Forecasts of the Stock Market and Macroeconomic Variables}

\author{
Kenneth R. Szulczyk \\ Curtin University Malaysia \\ Miri, Malaysia
}

\author{
Shibley Sadique \\ University of Rajshahi \\ Rajshahi, Bangladesh
}

Economic variables such as stock market indices, interest rates, and national output measures contain cyclical components. Forecasting methods excluding these cyclical components yield inaccurate out-of-sample forecasts. Accordingly, a three-stage procedure is developed to estimate a vector autoregression (VAR) with cyclical components. A Monte Carlo simulation shows the procedure estimates the parameters accurately. Subsequently, a VAR with cyclical components improves the root-mean-square error of out-of-sample forecasts by $50 \%$ for a stock market model with macroeconomic variables.

Keywords: $\quad$ Forecasting, Fourier regression, Fourier series, harmonic regression, error correction model, S\&P 500

\section{Introduction}

Vector autoregression (VAR) is used to forecast stationary multivariate time series (Lack, 2006). Several time series include growth rates, interest rates, inflation, and stock market returns. For non-stationary time series, researchers use error correction models (ECMs), which include short-term and long-term relationships and, in theory, provide better forecasts than a comparable VAR. ECMs utilize the cointegrating vectors to define long-term relationships (Christoffersen \& Diebold, 1998; Hoffman \& Rasche, 1996), and can forecast stock market indices, gross domestic product, and growing time series. However, the empirical evidence suggests many macroeconomic variables possess cyclical components. In this paper, these cyclical components are incorporated into VARs to strengthen forecasts.

A Fourier regression in (1) fits cyclical components with $y_{t}$ as the dependent variable and the $x_{t, j}$ as the explanatory variables. The $\beta_{j}$ are the parameters while $\varepsilon_{t}$

doi: 10.22237/jmasm/1539003896 | Accepted: February 26, 2018; Published: October 8, 2018.

Correspondence: Kenneth R. Szulczyk, ken@ken-szulczyk.com 
represents the white noise process, assumed to be $\varepsilon_{t} \sim \operatorname{iid}\left(0, \sigma^{2}\right)$. The $t$ indexes time and begins at $t=1$.

$$
\begin{aligned}
& y_{t}=\beta_{0}+\beta_{1} x_{t, 1}+\ldots+\beta_{j} x_{t, j}+\sum_{i=1}^{N} \alpha_{i} \cos \left(\frac{2 \pi t}{\tau_{i}}+\delta_{i}\right)+\varepsilon_{t} \text { and } \\
& \varepsilon_{t} \sim \operatorname{iid}\left(0, \sigma^{2}\right)
\end{aligned}
$$

The regression includes $N$ cosine terms that induce cycles into $y_{t}$. Each cosine term has an amplitude, a phase shift, and a cycle period (or frequency). The amplitude, $\alpha_{i}$, defines the maximum horizontal distance from the wave's center to the peak. The phase shift, $\delta_{i}$, moves the wave forward or backward horizontally from a fixed reference point. Finally, the cycle period, $\tau_{i}$, defines the vertical length from one peak to the next peak. The frequency, $\omega$, is related inversely to the cycle period through $\omega=2 \pi \tau$. The frequency indicates the number of oscillations occurring within a time period. Both terms are used interchangeably in this paper.

Trigonometric identities simplify (1) and make the equation more linear in parameters as shown in (2) by removing the phase shift.

$$
y_{t}=\beta_{0}+\beta_{1} x_{t, 1}+\ldots+\beta_{j} x_{t, j}+\sum_{i=1}^{n}\left(A_{i} \cos \left(\frac{2 \pi t}{\tau_{i}}\right)+B_{i} \cos \left(\frac{2 \pi t}{\tau_{i}}\right)\right)+\varepsilon_{t}
$$

Researchers refer to $A_{i}$ and $B_{i}$ as Fourier coefficients. A linear regression can fit $A_{i}$ and $B_{i}$ as parameters for fixed and known cycle periods because the cosine and sine terms become the explanatory variables (Fuller, 1996). Then ordinary least squares (OLS) estimates the parameters as (2) reduces to a standard linear regression.

Fourier regressions are used in three ways, which are not mutually exclusive. The first method employs a Fourier series to fit any function, even non-cyclical functions (Enders \& Holt, 2012). For example, the Fourier flexible form uses a Fourier series to fit a consumers' expenditure function that lacks cyclical components (Gallant, 1981). Many researchers use the Fourier flexible form to estimate unknown functions because it possesses well-behaved partial derivatives and uses few parameters. Furthermore, the parameters are easily estimated from sparse data (Fisher \& Fleissig, 1994; Fisher, Fleissig, \& Serletis, 2001; Fleissig \& Rossana, 2003; McMillen, 2001; McMillen \& Dombrow, 2001). 


\section{FOURIER VECTOR AUTOREGRESSION}

The second method uses a Fourier series to fit a seasonal cycle during the year. The seasonal cycle is the easiest to estimate (Kedem \& Fokianos, 2005; Meyer, 2000; Rayco-Solon, Fulford, \& Prentice, 2005; Simmons, 1990). Researchers add the explanatory variables $A_{i} \cos \left(2 \pi K_{i} t / \tau\right)$ and $B_{i} \sin \left(2 \pi K_{i} t / \tau\right)$ to a regression. All the terms inside the sine and cosine functions are known. The Fourier coefficients, $A_{i}$ and $B_{i}$, become the parameters in a linear regression model. Every term includes a harmonic, $K_{i}$, i.e. an integer of the base frequency. For example, if monthly data exhibit annual fluctuations, then the Fourier series with $\tau=12$ and $K_{1}=1$ fits this oscillation. If monthly data contain two cycles per year, then the Fourier coefficients with $\tau=12$ and $K_{2}=2$ accounts for this cycle, while the parameters $\tau=12$ and $K_{3}=3$ incorporate quarterly fluctuations in the data. In many instances, researchers do not know the data's frequencies, but they use trial and error to fit a variety of Fourier regression equations with different harmonics. Then they retain harmonics with at least one statistically significant Fourier coefficient.

The third method is similar to using a Fourier series to capture seasonal oscillations. The researchers set the cycle period $\tau_{i}$ equal to the number of observations in the dataset. Then they use trial and error to fit a variety of Fourier regression equations with different harmonics (Bahmani-Oskooee, Chang, \& Wu, 2014; Enders \& Holt, 2012; Jiang, Bahmani-Oskooee, \& Chang, 2015; Ludlow \& Enders, 2000). This approach works well if data exhibit a cycle that roughly equals the time span of the dataset or lies close to a significant harmonic. Many economic variables, as shown by Granger (1966), exhibit long cycle periods that roughly equal the time span of datasets. Incidentally, Fourier regression would fit these data well.

The way the cycle period is chosen causes several deficiencies. The cycle period, $\tau$, is set to equal to the number of observations in the dataset. Data are collected in known cycles, but this approach may be inappropriate for economic data because it is not known when oscillations begin and end in a variable, except for seasonal oscillations. Thus, researchers should treat the cycle periods $\tau_{i}$ as endogenous.

The second problem involves using harmonics to estimate the cyclical periods. For example, the United States experienced recessions in 1981, 1991, 2001, and 2007, about a 10-year cycle. For sample data between 1980 and 2014, a Fourier series would miss the recession cycle. The first harmonic has a 35-year cycle while the second harmonic equals 17.5 years. The third harmonic is 11.7 years, and the fourth equals 8.75 . Thus, the harmonic misses the ten-year cycle in the data. The Fourier regression would most likely fit the data poorly, even though the time series oscillates. 
The third deficiency is that economic variables may have multiple cosine and sine terms that reflect two or more frequencies with unrelated harmonics. For example, one frequency in an economic time series may reflect the Juglar business cycle while a second frequency reflects a Kondratiev wave. A Juglar business cycle originates from the recurring business booms and recessions that every economy experiences and lasts between 7 and 11 years. On the other hand, a Kondratiev wave stretches 50 years or longer and could reflect political, cultural, or generational change for a country (Korotayev \& Tsirel, 2010), or the country's adoption of a significant new technology, such as railroads, highways, airlines, computers, and the internet (Šmihula, 2009). A Juglar cycle differs from a Kondratiev wave and, thus, they are unrelated via harmonics.

\section{Methodology}

The three-stage procedure can estimate the parameters of a Fourier VAR and allow the investigation of the sampling properties. The procedure is similar to the procedure Omekara, Ekpenyong, and Ekerete (2013) used in their paper. The threestage procedure begins with a Fourier VAR in (3) with two frequencies, $\omega_{1}$ and $\omega_{2}$. The series $y_{t}\left(z_{t}\right)$ excludes lagged variables of $y_{t}\left(z_{t}\right)$ because the Fourier series replaces the lagged variables. At last, the Fourier VAR can include more frequencies and variables.

$$
\begin{aligned}
& y_{t}=\beta_{0}+\beta_{1} t+A_{1} \cos \left(\omega_{1} t\right)+B_{1} \sin \left(\omega_{1} t\right)+\beta_{2} z_{t-1}+\beta_{3} z_{t-2}+\varepsilon_{1, t} \\
& z_{t}=\alpha_{0}+\alpha_{1} t+A_{2} \cos \left(\omega_{2} t\right)+B_{2} \sin \left(\omega_{2} t\right)+\alpha_{2} y_{t-1}+\alpha_{3} y_{t-2}+\varepsilon_{2, t}
\end{aligned}
$$

The first stage fits the VAR in (4) without the Fourier series. The residuals, $\gamma_{1, t}$ and $\gamma_{2, t}$, contain the random noises and sinusoidal waveforms (Ludlow \& Enders, 2000). The trend variable removes any positive or negative growth over time, so the residuals oscillate along the time axis.

$$
\begin{aligned}
& y_{t}=\beta_{0}+\beta_{1} t+\beta_{2} z_{t-1}+\beta_{3} z_{t-2}+\gamma_{1, t} \\
& z_{t}=\alpha_{0}+\alpha_{1} t+\alpha_{2} y_{t-1}+\alpha_{3} y_{t-2}+\gamma_{2, t}
\end{aligned}
$$

The second stage calculates a periodogram in (5), also known as discrete Fourier transform (Poměnková \& Kapounek, 2010). The periodogram converts data from the time domain to the frequency domain and displays the frequencies present in a time series (Bloomfield, 2004; Kedem \& Fokianos, 2005; Strasek \& 


\section{FOURIER VECTOR AUTOREGRESSION}

Jagric, 2002). Many researchers compute the periodogram from the autocovariance functions (Bátorová, 2012) while, in this paper, the procedure uses the residuals $\hat{\gamma}_{i, t}$ from (4) to calculate the periodogram. The time series in (5) have $T$ observations, and $t$ ranges from 1 to $T$.

$$
I_{T(\omega)}=\frac{2}{T}\left\lfloor\left.\sum_{t=1}^{T} \hat{\gamma}_{i, t} \exp (-i \omega t)\right|^{2} \text {, where } \mathrm{i}=\sqrt{-1} \text { and } \omega \in[-\pi, \pi]\right.
$$

The periodogram forms an indicator function of two frequencies. The term $\exp (-i \omega t)$ creates a sinusoidal wave with a frequency $\omega$ with real and complex numbers. A loop starts at frequency $-\omega$ and takes the dot product between $\exp (-i \omega t)$ and the residuals $\hat{\gamma}_{i, t}$. When the frequencies of $\exp (-i \omega t)$ and $\hat{\gamma}_{i, t}$ match, the periodogram spikes at that frequency. When both frequencies differ, the dot product equals zero. At last, the loop stops at frequency $\omega$.

The VAR suffers from an omitted-variable bias. The biased parameter estimates from (4) could bias the frequencies in the periodogram. Consequently, the spikes on the periodogram indicate approximate frequencies in the residuals while the spike's relative height reflects the amplitude.

The last stage uses the dominant frequencies of the periodogram as starting values in a nonlinear least squares algorithm. Unfortunately, nonlinear least squares algorithms may experience two troubles in converging. First, if two frequencies lie too close together, then the algorithm could fail from multicollinearity. Second, the algorithm imposes no constraints on the frequency space. Consequently, two or more frequencies may converge to the same frequency, causing perfect multicollinearity. However, nonlinear least squares that have converged yields the parameter estimates in (3).

\section{Results}

A Monte Carlo simulation shows a three-stage procedure can accurately estimate a vector autoregression with cyclical components. The three-stage procedure is applied to a stock market model with an interest rate and national production measure to yield out-of-sample forecasts.

The Monte Carlo simulation begins with a known Fourier VAR in (6). The Fourier series in the $y_{t}$ has a frequency of 0.25 or a wavelength of 25.1 , while the Fourier series in $z_{t}$ has a frequency of 0.1 or a wavelength of 62.8 . Both frequencies differ from each other and are not related by harmonics. Although each regression 


\section{SZULCZYK \& SADIQUE}

in a Fourier VAR specifies one frequency, the lagged variable from the other series induces the second frequency. Finally, the $\varepsilon_{i, t}$ represents the identically and independently, normally distributed white noise process with a zero mean and unit variance.

$$
\begin{aligned}
& y_{t}=10+0.25 t+10 \cos (0.25 t)+7 \sin (0.25 t)+0.1 z_{t-1}+0.75 z_{t-2}+\varepsilon_{1, t} \\
& z_{t}=15+t+15 \cos (0.1 t)-20 \sin (0.1 t)-0.75 y_{t-1}+0.25 y_{t-2}+\varepsilon_{2, t}
\end{aligned}
$$

A random number generator creates the normally distributed white noise processes for $\varepsilon_{1, t}$, and $\varepsilon_{2, t}$, . Then a data-generating procedure in (3) calculates $y_{t}$ and $z_{t}$. The algorithm creates 202 observations and discards the first 100. In addition, the estimation of the Fourier VAR further reduces the observations by two by lagging two variables twice.

Figure 1 displays one simulation experiment. The time-series data appear typical because both variables display a positive trend over time while the data displays irregular oscillations. The low frequency in $z_{t}$ shows more prominently than the high frequency.
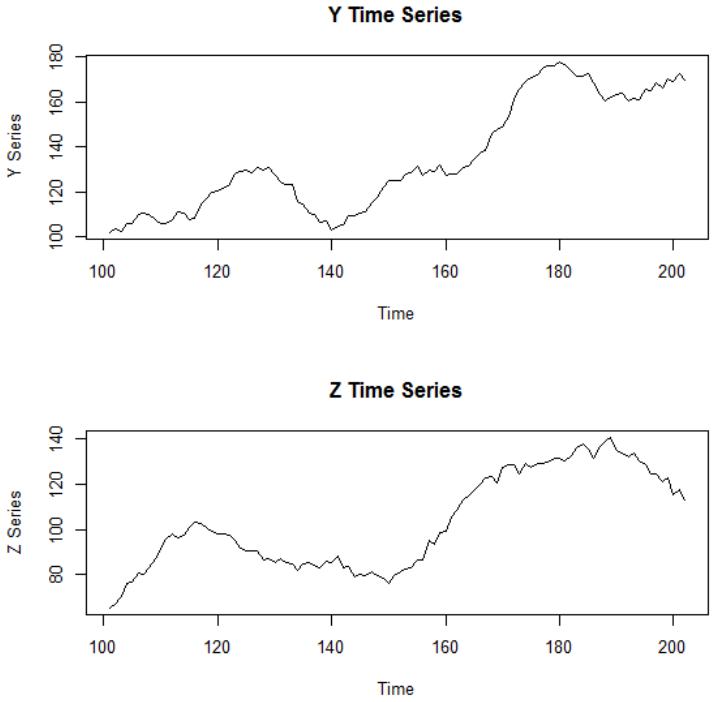

Figure 1. Data generated for the Fourier VAR 


\section{FOURIER VECTOR AUTOREGRESSION}
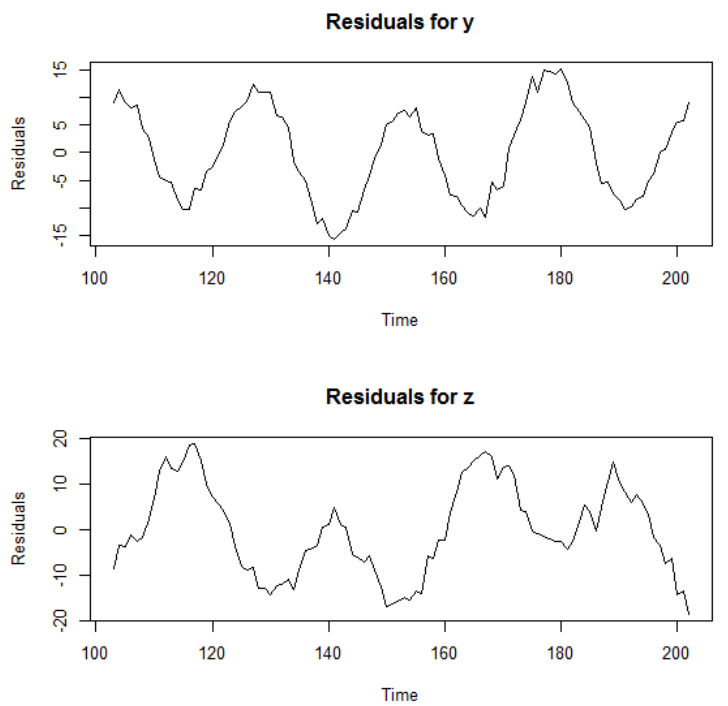

Figure 2. Residuals from the Fourier VAR without the Fourier series
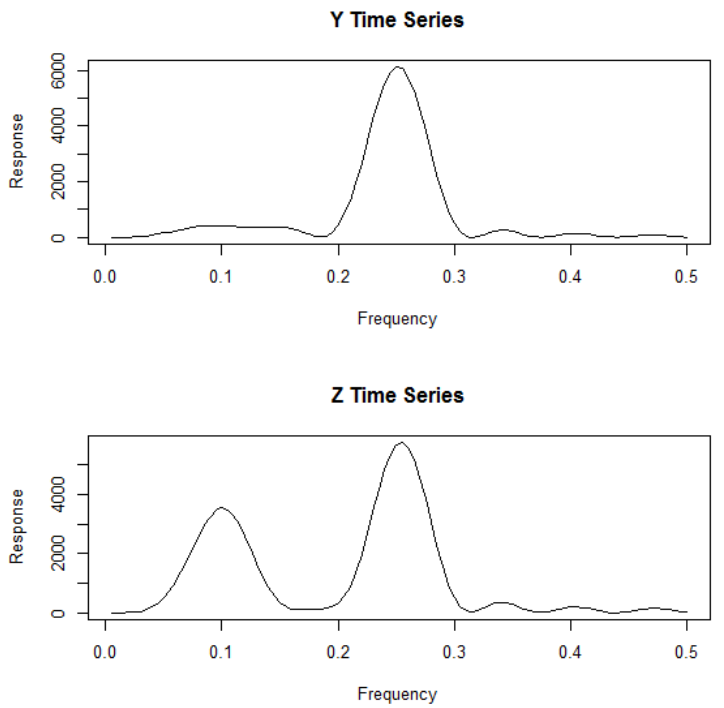

Figure 3. Periodogram of the residuals from (6)

The first stage estimates the Fourier VAR without the sine and cosine terms in (6) to obtain the residuals. Figure 2 displays the residuals from one experiment. 
Both time series display four peaks, indicating the higher frequency. However, the lower frequency remains hidden and not discernible.

The second stage estimates the periodogram of the residuals, which is shown in Figure 3. The residuals for $y_{t}$ exhibit one prominent frequency at 0.25 while the residuals for $z_{t}$ show two frequencies at 0.115 and 0.25 . Ironically, the higher frequency has a greater magnitude than the lower frequency. The periodogram estimates the high frequency accurately while the lower frequency is inaccurate, which could result from the omitted variable bias. Moreover, the periodogram displays weak frequencies lying adjacent to the primary two frequencies, which may indicate leakages. A leakage causes one frequency to artificially elevate the magnitude of other frequencies (Granger, 1966).

The last stage uses the dominant frequencies of the periodogram as starting values in a nonlinear least squares algorithm. The $y_{t}$ series uses a 0.25 frequency while the $z_{t}$ series utilizes 0.11 as starting values. Because the data in the VAR behaves well, the algorithm converges with no trouble.

Table 1 shows the statistical properties of the Monte Carlo simulation. The simulation generates 300 samples. Each sample creates a new set of identically and independently, normally distributed random numbers to calculate $y_{t}$ and $z_{t}$ using (3). Furthermore, the simulation program creates 202 observations and discards the first 100. Table 1 shows the mean, population standard deviation (PSD), and coefficient of variation $(\mathrm{CV})$ for the parameter estimates along with the actual parameter values.

Table 1. The Monte Carlo simulation of the Fourier VAR

\begin{tabular}{|c|c|c|c|c|c|}
\hline & \multirow[b]{2}{*}{ Parameter } & \multirow[b]{2}{*}{ True Value } & \multicolumn{3}{|c|}{ Statistics } \\
\hline & & & Mean & PSD & CV (\%) \\
\hline \multirow[t]{7}{*}{$y_{t}$} & Intercept & 10.0000 & 9.9378 & 0.5728 & 5.7638 \\
\hline & Trend & 0.2500 & 0.2500 & 0.0062 & 2.4641 \\
\hline & Cos & 10.0000 & 10.0062 & 0.4521 & 4.5184 \\
\hline & Sin & 7.0000 & 6.9555 & 0.6233 & 8.9611 \\
\hline & Frequency & 0.2500 & 0.2500 & 0.0004 & 0.1571 \\
\hline & $Z_{t-1}$ & 0.1000 & 0.0992 & 0.0412 & 41.5134 \\
\hline & $z_{t-2}$ & 0.7500 & 0.7515 & 0.0408 & 5.4309 \\
\hline \multirow[t]{7}{*}{$z_{t}$} & Intercept & 15.0000 & 15.0461 & 0.5986 & 3.9788 \\
\hline & Trend & 1.0000 & 1.0011 & 0.0133 & 1.3254 \\
\hline & Cos & 15.0000 & 15.0472 & 0.6777 & 4.5038 \\
\hline & Sin & -20.0000 & -19.9774 & 0.4826 & -2.4155 \\
\hline & Frequency & 0.1000 & 0.1000 & 0.0002 & 0.1997 \\
\hline & $y_{t-1}$ & -0.7500 & -0.7477 & 0.0406 & -5.4239 \\
\hline & $y_{t-2}$ & 0.2500 & 0.2461 & 0.0410 & 16.6523 \\
\hline
\end{tabular}




\section{FOURIER VECTOR AUTOREGRESSION}
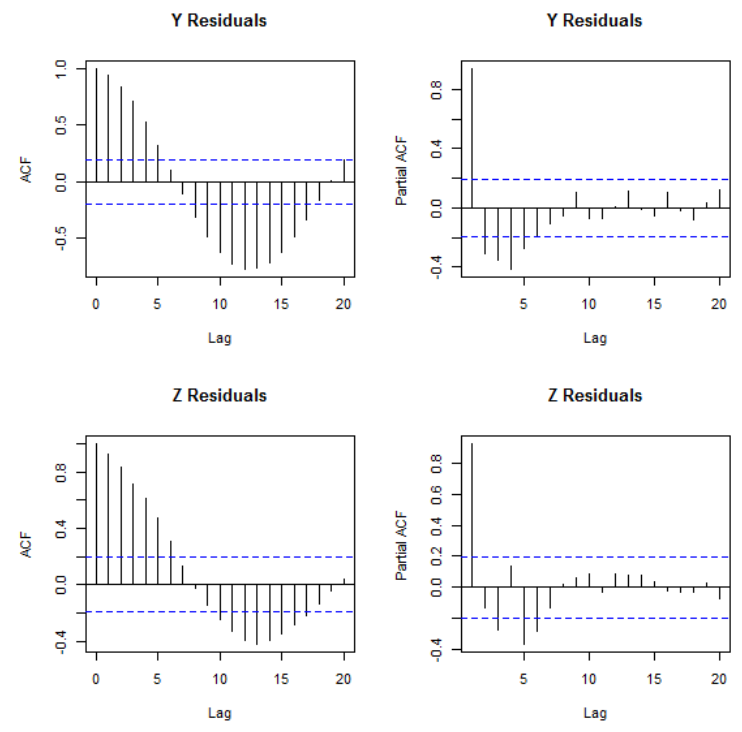

Figure 4. The ACF and PACF plots of $y$ and $z$ residuals from the Fourier VAR

The means of the parameter estimates lie close to their actual parameter values in Table 1. The frequencies exhibit the lowest coefficient of variation while the lagged values have the highest. The first lagged value, $z_{t-1}$, has a coefficient of variation of $41.5 \%$ while the second, $y_{t-2}$, exhibits $16 \%$. The lagged values are stochastic and display a wider variance than the other parameters. The coefficients of variation for the other parameters are low, and the repeated sampling of the algorithm appears quite robust.

The study of Fourier VARs uncovers two phenomena: For example, suppose a researcher treats oscillating data as an autoregressive-moving average (ARMA) process. Figure 4 displays the autocorrelation function (ACF) and partial autocorrelation function (PACF) with the dashed lines for the 95\% confidence interval. The top ACF and PACF plots are for the $y_{t}$ series while the bottom plots are for the $z_{t}$. Both ACF plots display an oscillating wave. Furthermore, the PACF plots for both $y_{t}$ and $z_{t}$ have several statistically significant lags. If both the ACF and PACF tail off to zero, a linear regression is estimated with an $\operatorname{ARMA}(1,1)$ structure imposed on the residuals. The autoregressive (AR) parameter estimate equals $0.9278(0.9337)$ for $y_{t}\left(z_{t}\right)$ residuals while the moving average (MA) parameter estimate equals 0.3169 (0.0763). (The results are available upon request.) Thus, a prominent feature of oscillating variables is the $\operatorname{AR}(1)$ parameter estimate always lies close to one, which is referred to as a unit root. Intuitively, any two 
adjacent points on a sine or cosine wave share almost the same magnitude. Finally, the Augmented Dickey-Fuller (ADF), Phillips-Perron (PP) (Phillips \& Perron, 1988), and Kwiatkowski-Phillips-Schmidt-Shin (KPSS) (Kwiatkowski, Phillips, Schmidt, \& Shin, 1992) unit root tests indicate mix results. The unit root tests are not reported but available on request.

For the second phenomenon, the cyclical components are not exactly shaped as sine and cosine waves. For example, (7) creates a triangular wave with a frequency of 0.1257 (or cycle period of 50), a zero phase shift, and an amplitude of 15.7. The number of observations equals 100. A random number generator creates the independently, identically, and normally distributed white noise process.

$$
y_{t}=10 \sin ^{-1}(\cos (0.1257 t))+\varepsilon_{t} \text { and } \varepsilon_{t} \sim \operatorname{iidN}(0,1)
$$

One such experiment is shown in Figure 5 using (7) to generate the data, $y_{t}$, with its fitted cosine wave. The three-stage procedure yields the regression as $\hat{y}_{t}=12.8386 \cos (0.1193 t)-0.4548 \sin (0.1193 t)$ with parameter estimates in Table 2. The Fourier series fits the data well with an $R^{2}$ of 0.97 . Unfortunately, the fitted cosine wave underestimates the triangular waveform at the peaks around observations $0,25,50,75$, and 100 . The residuals spike around these observations and induce autocorrelation into the residuals.

Shown in Figure 6 are the ACF and PACF plots for the residuals from fitting the triangular wave. Both plots oscillate and tail off to zero indicating $\operatorname{ARMA}(1,1)$. Unfortunately, adding another cosine term to the regression may not reduce autocorrelation. The triangular waves diverge from the shape of sine and cosine waves and, thus, adding more sine and cosine waves may not eliminate the problem. Finally, the Fourier regression has a high $R^{2}$ as Table 2 indicates. Adding more Fourier terms may not necessarily improve the fit.

Table 2. Using a Fourier series to fit a triangular wave

\begin{tabular}{rr} 
Variables & Triangular Wave \\
\hline Cos & $12.8386^{*}$ \\
& $(0.0000)$ \\
Sin & -0.4548 \\
& $(0.2840)$ \\
Frequency & $0.1193^{*}$ \\
& $(0.0000)$ \\
$R^{2}$ & 0.9729 \\
\hline
\end{tabular}

Note: * denotes the $0.1 \%$ significance level with the $p$-values in the parentheses 


\section{FOURIER VECTOR AUTOREGRESSION}

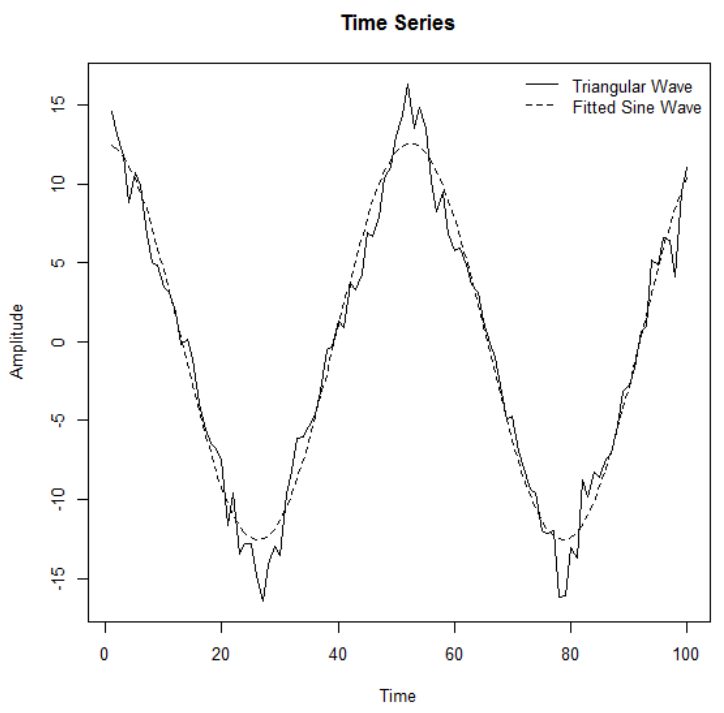

Figure 5. The triangular wave and its fitted Fourier regression
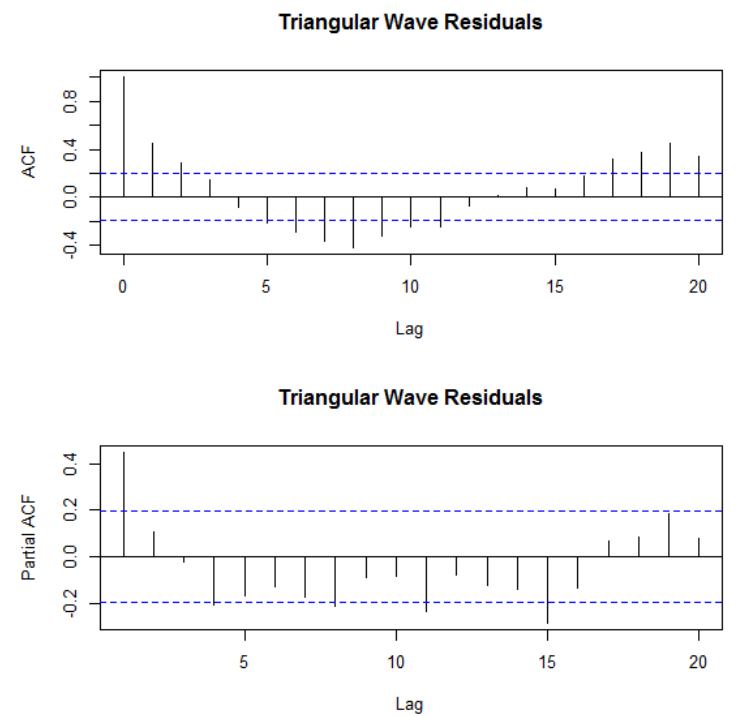

Figure 6. The ACF and PACF plots for the triangular wave's residuals 


\section{The Stock Market Model}

The stock market is viewed as a health gauge of the economy because it correlates with macroeconomic variables such as interest rates (INT) and nominal gross domestic product (NGDP). For example, savings are transferred from bank accounts to the stock market to earn a higher return as interest rates fall. Moreover, a growing economy experiences more inflation and produces more goods and services. Thus, nominal GDP rises. Meanwhile, greater income may be earned, and subsequently invested into the stock market, raising stock prices.

GDP data, interest rates, and other data are averaged to match the nominal GDP quarterly data. The sample starts in 1994 Q3 and ends at 2007 Q4. Observations between 2008 Q1 and 2014 Q4 comprise the out-of-sample forecasts. Although data before 1994 exists, the characteristics of the waves may change over time from structural changes in the economy such as financial deregulation (Hughes Hallett \& Richter, 2004).

Time series analysis always begins with unit root tests. The absence of a unit root indicates a stationary time series. Reported in panel A of Table 3 are the Phillips-Perron (PP) (Phillips \& Perron, 1988) and Kwiatkowski-Phillips-SchmidtShin (KPSS) (Kwiatkowski et al., 1992) tests on the levels and first difference of the sample with $p$-values in the parenthesis. A formula selects the number of lags

Table 3. Unit root and cointegration tests

\begin{tabular}{|c|c|c|c|c|}
\hline \multirow{2}{*}{ Panel A: Unit rc } & \multicolumn{2}{|c|}{ Levels } & \multicolumn{2}{|c|}{ First difference } \\
\hline & PP & KPSS & PP & KPSS \\
\hline \multirow[t]{2}{*}{ S\&P500 } & -6.4442 & $1.3899^{* *}$ & $-53.8010^{\star \star}$ & 0.1546 \\
\hline & $(0.7391)$ & $(0.0100)$ & $(0.0100)$ & $(0.1000)$ \\
\hline \multirow[t]{2}{*}{ Interest rate } & -9.4548 & $1.8212^{\star *}$ & $-38.9680^{\star *}$ & 0.0835 \\
\hline & $(0.5608)$ & $(0.0100)$ & $(0.0100)$ & $(0.1000)$ \\
\hline \multirow[t]{2}{*}{ Nominal GDP } & -7.3490 & $2.8132^{* *}$ & $-47.5760^{* *}$ & 0.0971 \\
\hline & $(0.6855)$ & $(0.0100)$ & $(0.0100)$ & $(0.1000)$ \\
\hline
\end{tabular}

Panel B: Number of cointegration vectors

\begin{tabular}{|c|c|c|c|c|}
\hline \multirow[b]{2}{*}{$\mathrm{H}_{0}$} & \multicolumn{2}{|c|}{ Trace test } & \multicolumn{2}{|c|}{ Eigenvalue test } \\
\hline & $5 \%$ critical value & Statistic & $5 \%$ critical value & Statistic \\
\hline$r=0$ & 34.9100 & $53.0400^{\star \star *}$ & 22.0000 & $43.0600^{\star \star \star}$ \\
\hline$r \leq 1$ & 19.9600 & 9.9800 & 15.6700 & 6.6100 \\
\hline$r \leq 2$ & 9.2400 & 3.3700 & 9.2400 & 3.3700 \\
\hline
\end{tabular}

Note: ${ }^{* * *}$ indicates the 0.05 significance level; $\mathrm{R}$ cannot extrapolate $p$-values that fall below 0.01 or exceed 0.1 for the unit root tests 


\section{FOURIER VECTOR AUTOREGRESSION}

Table 4. Unrestricted error correction model (ECM)

\begin{tabular}{|c|c|c|c|}
\hline Variables & $\Delta S_{Q} \& P_{t}$ & $\Delta$ Interest $_{t}$ & $\Delta$ NGDP $_{t}$ \\
\hline \multirow[t]{2}{*}{ Constant } & 942.9174 & -6.1469 & 781.1175 \\
\hline & (0.1943) & $(0.0811)$ & $(0.2180)$ \\
\hline \multirow[t]{2}{*}{ Seasonal $D_{1}$} & -43.6319 & -0.1148 & -19 \\
\hline & $(0.0587)$ & $(0.2934)$ & $(0.3248)$ \\
\hline \multirow[t]{2}{*}{ Seasonal $D_{2}$} & 14.2335 & -0.0609 & -6.7931 \\
\hline & (0.5438) & $(0.5887)$ & $(0.7397)$ \\
\hline \multirow[t]{2}{*}{ Seasonal $D_{3}$} & -11.1913 & -0.278 & -21.3 \\
\hline & (0.6242) & $(0.0144)$ & $(0.2882)$ \\
\hline \multirow[t]{2}{*}{$\Delta S \& P_{t-1}$} & 0.0762 & $0.0029^{*}$ & $0.3104^{* * *}$ \\
\hline & $(0.64$ & $(0.0$ & $(0.0$ \\
\hline \multirow[t]{2}{*}{$\Delta \mathrm{INT}_{t-1}$} & 32.9585 & $0.3683^{* * *}$ & 47.8854 \\
\hline & $(0.2755)$ & $(0.0140)$ & $(0.0$ \\
\hline \multirow[t]{2}{*}{$\Delta \mathrm{NGDP}_{t-1}$} & 0.1394 & 0.0 & -0.1890 \\
\hline & $(0.5436)$ & $(0.5$ & $(0.3474)$ \\
\hline \multirow[t]{2}{*}{$S \& P_{t-2}$} & $-0.1699^{*}$ & 0.0006 & -0.0218 \\
\hline & $(0.02$ & $(0.0$ & $(0.7337)$ \\
\hline \multirow[t]{2}{*}{$\mathrm{INT}_{t-2}$} & 29.5453 & $-0.2281^{* * *}$ & 4.2782 \\
\hline & $(0.1087)$ & $(0.0119)$ & $(0.7871)$ \\
\hline \multirow[t]{2}{*}{$\mathrm{NGDP}_{t-2}$} & -0.1420 & 0.0010 & -0.0990 \\
\hline & $(0.2088)$ & & $(0.3143)$ \\
\hline \multirow[t]{2}{*}{ Trend $_{t-2}$} & 22.6009 & -0.1532 & 15.9013 \\
\hline & (0.1898) & $(0.0673)$ & $(0.2892)$ \\
\hline $\bar{R}^{2}$ & 0.2197 & 0.5920 & 0.8910 \\
\hline RMSE & 52.6071 & 0.2650 & 44.9239 \\
\hline
\end{tabular}

Note: ${ }^{* * *}$ indicates the $5 \%$ significance level, ${ }^{* *}$ indicates $1 \%$, and ${ }^{* *}$ signifies $0.1 \% ; p$-values are in parenthesis

for both tests. The PP uses three lags while the KPSS utilizes two. The PP null hypothesis is the time series has a unit root while rejecting the null for KPSS indicates a unit root. Consequently, all time series possess unit roots at the levels, but the unit roots disappear after taking the first difference. In this case, a first difference transforms the time series into a stationary process.

The second step of time series analysis is comprised of cointegration tests. Three variables, in this case, are cointegrated if a linear combination of the variable creates a stationary process. Panel B of Table 3 shows the Johansen (1991) cointegration tests on the time series using both the trace and maximum eigenvalue. Both tests indicate the sample has one cointegration vector. Low frequencies in time series constitute the long-run linear relationship between variables. Consequently, the cointegration vector restricts low frequencies in the time series 
(Christoffersen \& Diebold, 1998). Shown in Table 4 is the estimation of a longterm error correction model (ECM) with seasonal dummies for the sample between 1994 Q3 and 2007 Q4 and with one cointegration vector. Many settings are tried to obtain the best forecast from an ECM, which is compared to the forecast of the Fourier VAR.

The first stage of the Fourier VAR estimates (8) without the sine and cosine terms. A linear trend detrends the residuals, so that they oscillate along the time axis.

$$
\begin{aligned}
& \mathrm{S} \& \mathrm{P}_{t}=\beta_{1,1}+\beta_{1,2} t+\beta_{1,5} \mathrm{INT}_{t-1}+\beta_{1,6} \mathrm{INT}_{t-2}+\beta_{1,7} \mathrm{NGDP}_{t-1} \\
& +\beta_{1,8} \mathrm{NGDP}_{t-2}+\gamma_{1, t}
\end{aligned}
$$

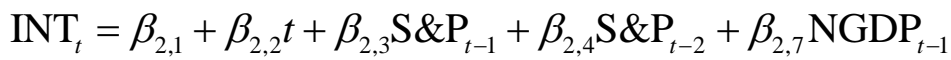

$$
\begin{aligned}
& +\beta_{2,8} \mathrm{NGDP}_{t-2}+\gamma_{2, t} \\
& \mathrm{NGDP}_{t}=\beta_{3,1}+\beta_{3,2} t+\beta_{3,3} \mathrm{~S} \& \mathrm{P}_{t-1}+\beta_{3,4}{\mathrm{~S} \& \mathrm{P}_{t-2}}+\beta_{3,5} \mathrm{INT}_{t-1} \\
& +\beta_{3,6} \mathrm{INT}_{t-2}+\gamma_{3, t}
\end{aligned}
$$
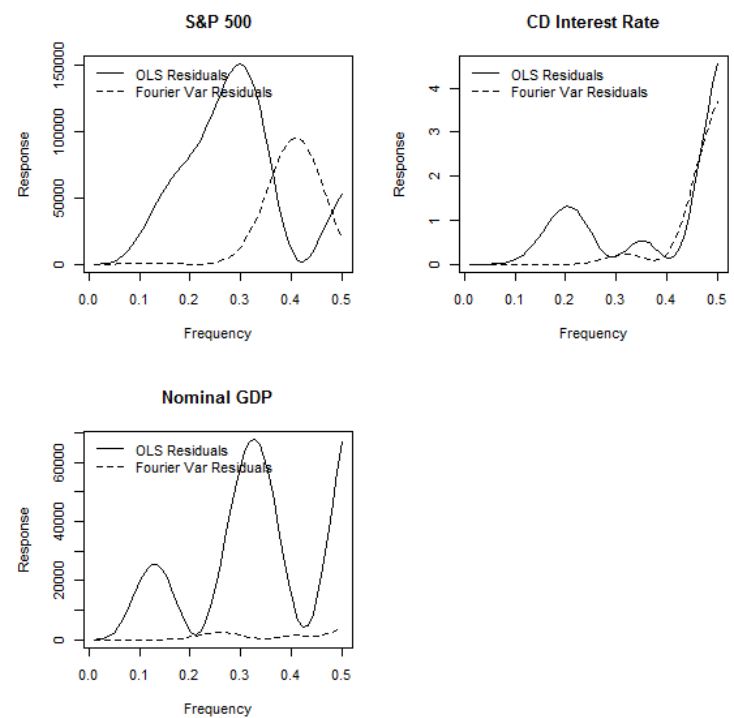

Figure 7. Periodograms of the residuals from the OLS and Fourier VAR 


\section{FOURIER VECTOR AUTOREGRESSION}

The second stage plots the periodogram of the residuals of (8) in Figure 7. The VAR could suffer from an omitted-variable bias, which provides the approximate frequencies of the system. The S\&P500 Index shows three prominent frequencies around $0.2,0.31$, and 0.5 while the interest rate has frequencies roughly 0.21 and 0.5 . Finally, the nominal GDP displays frequencies of $0.13,0.33$, and 0.5 .

The last stage involves selecting the frequencies to include in the model. The frequencies represent different cycles in the economy. The Fourier VAR in (9) utilizes one dominant frequency for each time series. The analysis uses many different starting frequencies to locate frequencies that yield the lowest residual standard error (RSE) and fits the data well.

$$
\begin{aligned}
& \mathrm{S} \& \mathrm{P}_{t}=\beta_{1,1}+\beta_{1,2} t+\beta_{1,3} \cos \left(\omega_{1} t\right)+\beta_{1,4} \sin \left(\omega_{1} t\right)+\beta_{1,5} \mathrm{INT}_{t-1}+\beta_{1,6} \mathrm{INT}_{t-2} \\
& +\beta_{1,7} \mathrm{NGDP}_{t-1}+\beta_{1,8} \mathrm{NGDP}_{t-2}+\gamma_{1, t}
\end{aligned}
$$

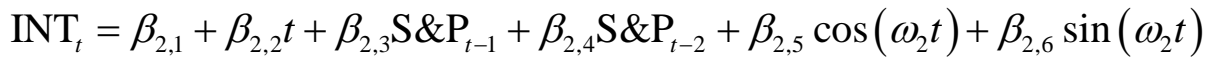

$$
\begin{aligned}
& +\beta_{2,7} \mathrm{NGDP}_{t-1}+\beta_{2,8} \mathrm{NGDP}_{t-2}+\gamma_{2, t}
\end{aligned}
$$

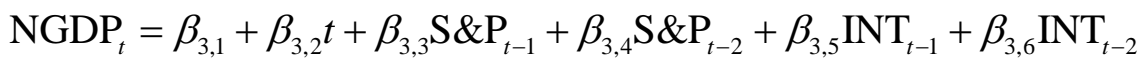

$$
\begin{aligned}
& +\beta_{3,7} \cos \left(\omega_{3} t\right)+\beta_{3,8} \sin \left(\omega_{3} t\right)+\gamma_{3, t}
\end{aligned}
$$
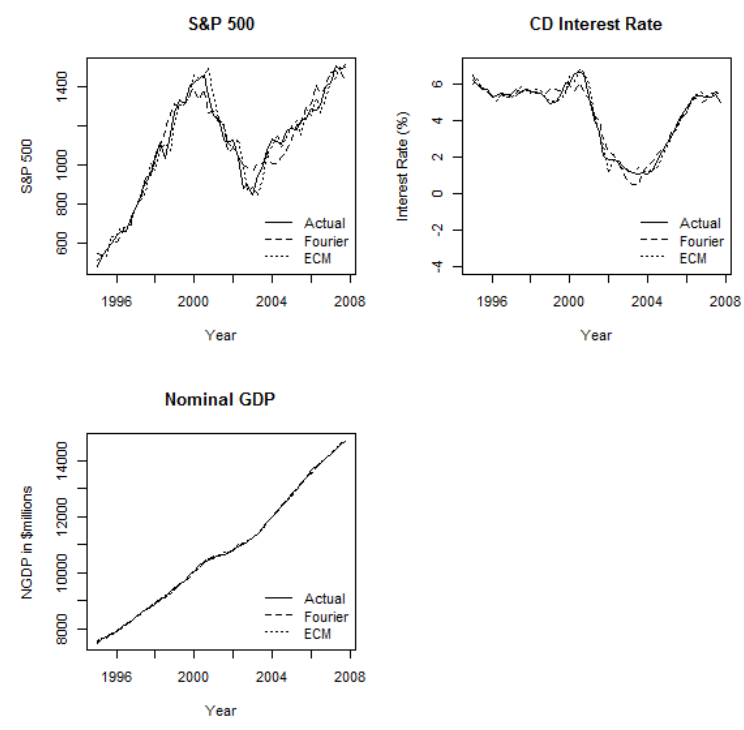

Figure 8. The Fourier and ECM fits 
SZULCZYK \& SADIQUE

Table 5. The Fourier VAR

\begin{tabular}{rrrr} 
Variables & S\&Pt & INTt & NGDPt \\
\hline Constant & $3713.4460^{*}$ & $-30.7417^{*}$ & $6481.5978^{*}$ \\
& $(0.0000)$ & $(0.0000)$ & $(0.0000)$ \\
Trend & $70.3599^{*}$ & $-0.7813^{*}$ & $128.8040^{*}$ \\
& $(0.0001)$ & $(0.0000)$ & $(0.0000)$ \\
Cos & $-130.7524^{*}$ & $-0.6024^{* * *}$ & $299.7558^{*}$ \\
& $(0.0000)$ & $(0.0222)$ & $(0.0000)$ \\
Sin & $-228.6712^{*}$ & -0.1841 & $-124.7799^{* * *}$ \\
& $(0.0000)$ & $(0.6593)$ & $(0.0238)$ \\
Frequency & $0.2085^{*}$ & $0.1978^{*}$ & $0.1190^{*}$ \\
& $(0.0000)$ & $(0.0000)$ & $(0.0000)$ \\
S\&Pt-1 & -- & 0.0008 & $0.4657^{*}$ \\
& & $(0.5756)$ & $(0.0000)$ \\
S\&Pt-2 & -- & 0.0009 & 0.1816 \\
& & $(0.4652)$ & $(0.0892)$ \\
INT $_{t-1}$ & -5.0824 & -- & $60.6532^{* *}$ \\
& $(0.8915)$ & & $(0.0032)$ \\
INT $_{t-2}$ & 40.0972 & -- & -13.5746 \\
& $(0.2172)$ & & $(0.3956)$ \\
NGDP $_{t-1}$ & 0.3998 & $0.0051^{*}$ & - \\
& $(0.1293)$ & $(0.0007)$ & \\
NGDP $_{t-2}$ & $-0.8454^{*}$ & 0.0000 & -- \\
& $(0.0008)$ & $(0.9915)$ & \\
RMSE & 62.4233 & 0.4015 & 36.9256 \\
\hline
\end{tabular}

Note: ${ }^{* * *}$ indicates the $5 \%$ significance level, ${ }^{* *}$ indicates $1 \%$, and ${ }^{*}$ signifies $0.1 \%$; $p$-values are in parenthesis and are adjusted using Newey-West with $\mathrm{AR}(1)$

Shown in Table 5 are the parameter estimates for the Fourier VAR. The $p$ values are corrected by using Newey and West (1987) that reduce the problems of autocorrelation and heteroscedasticity. Both the S\&P 500 and interest rate have a frequency of 0.206 or 7.6 years, corresponding to a Juglar business cycle. On the other hand, the nominal GDP has a frequency of 0.1184 or a 13.3-year cycle, which does not correspond to a Juglar or Kuznets infrastructure investment cycle. Lagged values of the nominal GDP influence both the S\&P 500 and interest rate while lagged values of the S\&P 500 and interest rates act on the nominal GDP.

Figure 7 also includes the periodogram of the residuals from the Fourier VAR. Nominal GDP and interest rate account for the 0.21 frequency. However, the S\&P still displays a prominent frequency oscillating around 0.4 . 


\section{FOURIER VECTOR AUTOREGRESSION}

Table 6. Forecasting test

\begin{tabular}{rrrr} 
Panel A: ECM & & & \\
& S\&P & INT & NGDP \\
\hline RMSE & 339.6479 & 4.7773 & 1394.5103 \\
Campbell-Thompson $R_{\mathrm{os}}^{2}$ & 0.4025 & $(0.5695)$ & 0.9264 \\
Clark-West Statistic & $4.5514^{*}$ & -7.3834 & $12.8323^{*}$ \\
& $(0.0000)$ & $(1.0000)$ & $(0.0000)$ \\
Diebold-Mariano Test & 1.2702 & -7.0184 & $12.2940^{*}$ \\
& $(0.1074)$ & $(1.0000)$ & $(0.0000)$ \\
\hline
\end{tabular}

\begin{tabular}{rrrr} 
Panel B: Fourier VAR & & & \\
& S\&P & INT & NGDP \\
\hline RMSE & 163.8864 & 2.6915 & 309.8847 \\
Campbell-Thompson $R_{\mathrm{oS}}^{2}$ & 0.8609 & 0.5018 & 0.9964 \\
Clark-West Statistic & $3.7703^{*}$ & $9.6969^{*}$ & $13.9088^{*}$ \\
& $(0.0001)$ & $(0.0000)$ & $(0.0000)$ \\
Diebold-Mariano Test & $3.0375^{*}$ & $5.5999^{*}$ & $12.5230^{*}$ \\
& $(0.0026)$ & $(0.0000)$ & $(0.0000)$ \\
\hline
\end{tabular}

Note: * denotes the $0.1 \%$ significance level, with the $p$-values in parenthesis

The fits of the Fourier VAR and ECM are compared with the data in Figure 8. (Tables 4 and 5 also include the root-mean-square error (RMSE).) The ECM fits the S\&P500 and CD interest rate better than the Fourier VAR while the Fourier VAR fits the nominal GDP better.

Several tests evaluate the out-of-sample forecast performance. For instance, the root-mean-square error can determine which forecast predicts the time series better (Hassani, Soofi, \& Zhigljavsky, 2013; Hassani, Webster, Silva, \& Heravi, 2015). Table 6 shows both the Fourier VAR and ECM forecasts for 28 quarters between 2008 and 2014. The table includes the root-mean-square error (RMSE) and the Campbell-Thompson, Clark-West, and Diebold-Mariano statistics. Furthermore, the Campbell-Thompson statistic (Campbell \& Thompson, 2007) calculates an out-of-sample (OS) $R_{\mathrm{OS}}^{2}$, which is comparable to the $R^{2}$ in linear regression. The $R_{\mathrm{OS}}^{2}$ compares the out-of-sample forecast to the historical, insample mean because Welch and Goyal (2008) found many economic variables fail to surpass the historical mean as a forecast. The $R_{\mathrm{OS}}^{2}$ lies between $(-\infty, 1]$, and a positive $R_{\mathrm{OS}}^{2}$ outperforms the mean. All forecasts for both the ECM and Fourier VAR outperform the historical mean except for the ECM interest rate forecast. The 
Clark-West statistic (Clark \& West, 2007) tests whether a positive $R_{\mathrm{OS}}^{2}$ is statistically significant. All $R_{\mathrm{OS}}^{2}$ for both the ECM and Fourier VAR is statistically significant except the ECM interest rate forecast. Finally, the Diebold and Mariano test (Diebold \& Mariano, 1995) determines whether the forecast surpasses the historical average using a one-tail test. All Fourier VAR forecasts are statistically significant while only the ECM nominal GDP is statistically significant. Thus, the Fourier VAR yields half the RMSE of the ECM and outperforms the ECM in forecasting the stock market with macroeconomic variables.

The time series have significant cyclical components that improve forecasts which Figure 9 reflects. The Fourier VAR of the S\&P500 captures the drop during the 2008 Global Financial Crisis, but the standard ECM misses it. The Fourier VARs predicts the nominal GDP and interest rate well while the ECM barely dips at all. Furthermore, the Fourier VAR forecast shows the interest rate dips below zero. Negative interest rates could be set to zero, which further improves the forecasts for all-time series. At last, a comparable VAR provides a better forecast than the ECM and supports Christoffersen and Diebold (1998) that cointegration may not improve forecasts. However, the Fourier VAR still forecasts better than the standard VAR. The standard VAR estimation is available on request.
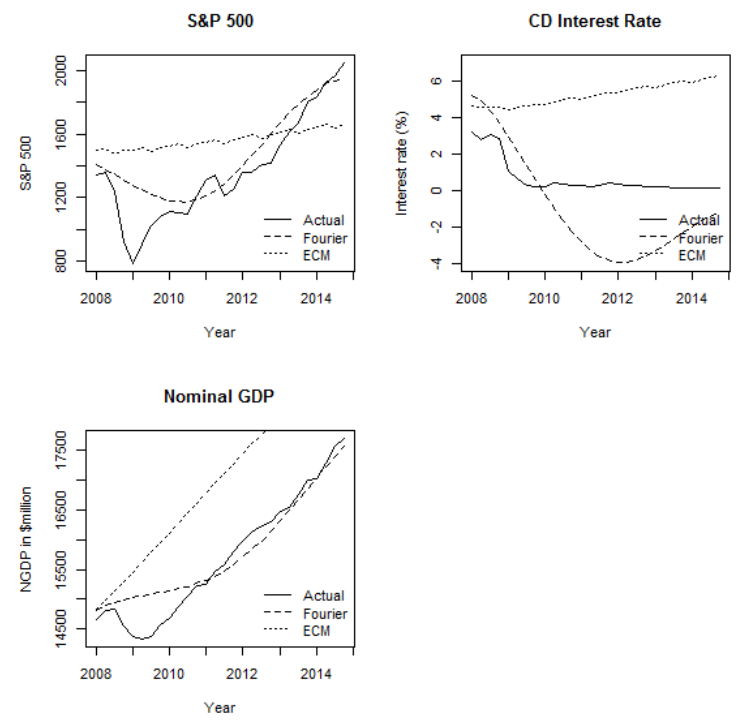

Figure 9. The Fourier and ECM out-of-sample forecasts 


\section{FOURIER VECTOR AUTOREGRESSION}

\section{Conclusion}

The stock market index, interest rate, and national production measure contain cyclical components. A three-stage procedure identifies the frequencies of the cyclical components and allows a parsimonious estimation of a Fourier VAR. A Monte Carlo simulation shows the three-stage procedure calculates the parameter estimates of a Fourier VAR, and a stock model with an interest rate and national production measure improves the out-of-sample forecast with half of the RMSE. For policy implications, investors in a stock market can use a Fourier VAR forecast to determine the market's trough and buy bargain stocks when stock prices are low. In addition, economists and politicians can utilize a Fourier VAR forecast to determine the duration and severity of downturns in the economy as measured by a national production measure.

\section{References}

Bahmani-Oskooee, M., Chang, T., \& Wu, T. (2014). Revisiting purchasing power parity in African countries: Panel stationary test with sharp and smooth breaks. Applied Financial Economics, 24(22), 1429-1438. doi:

10.1080/09603107.2014.925068

Bátorová, I. (2012). Spectral techniques for economic time series (Unpublished doctoral dissertation). Comenius University, Slovakia. Retrieved from http://www.iam.fmph.uniba.sk/studium/efm/phd/batorova/autoreferat.pdf

Bloomfield, P. (2004). Fourier analysis of time series: An introduction (2nd ed.). New York, NY: John Wiley \& Sons. doi: 10.1002/0471722235

Campbell, J. Y., \& Thompson, S. B. (2007). Predicting excess stock returns out of sample: Can anything beat the historical average? The Review of Financial Studies, 21(4), 1509-1531. doi: 10.1093/rfs/hhm055

Christoffersen, P. F., \& Diebold, F. X. (1998). Cointegration and longhorizon forecasting. Journal of Business \& Economic Statistics, 16(4), 450-456. doi: $10.2307 / 1392613$

Clark, T. E., \& West, K. D. (2007). Approximately normal tests for equal predictive accuracy in nested models. Journal of Econometrics, 138(1), 291-311. doi: 10.1016/j.jeconom.2006.05.023

Diebold, F. X., \& Mariano, R. S. (1995). Comparing predictive accuracy. Journal of Business \& Economic Statistics, 13(3), 253-263. doi: 10.2307/1392185 
Enders, W., \& Holt, M. T. (2012). Sharp breaks or smooth shifts? An investigation of the evolution of primary commodity prices. American Journal of Agricultural Economics, 94(3), 659-673. doi: 10.1093/ajae/aar162

Fisher, D., \& Fleissig, A. (1994). Money demand in a flexible dynamic Fourier expenditure system. Federal Reserve Bank of St. Louis Review, 47(2), 117-128. doi: 10.20955/r.76.117-128

Fisher, D., Fleissig, A. R., \& Serletis, A. (2001). An empirical comparison of flexible demand system functional forms. Journal of Applied Econometrics, 16(1), 59-80. doi: 10.1002/jae.585

Fleissig, A. R., \& Rossana, R. J. (2003). Are consumption and government expenditures substitutes or complements? Morishima elasticity estimates from the Fourier flexible form. Economic Inquiry, 41(1), 132-146. doi: 10.1093/ei/41.1.132

Fuller, W. A. (1996). Introduction to statistical time series. New York, NY: John Wiley \& Sons.

Gallant, A. R. (1981). On the bias in flexible functional forms and an essentially unbiased form: The Fourier flexible form. Journal of Econometrics, 15(2), 211-245. doi: 10.1016/0304-4076(81)90115-9

Granger, C. W. J. (1966). The typical spectral shape of an economic variable. Econometrica, 34(1), 150-161. doi: 10.2307/1909859

Hassani, H., Soofi, A. S., \& Zhigljavsky, A. (2013). Predicting inflation dynamics with singular spectrum analysis. Journal of the Royal Statistical Society: Series A (Statistics in Society), 176(3), 743-760. doi: 10.1111/j.1467985x.2012.01061.x

Hassani, H., Webster, A., Silva, E. S., \& Heravi, S. (2015). Forecasting U.S. tourist arrivals using optimal singular spectrum analysis. Tourism Management, 46, 322-335. doi: 10.1016/j.tourman.2014.07.004

Hoffman, D. L., \& Rasche, R. H. (1996). Assessing forecast performance in a cointegrated system. Journal of Applied Econometrics, 11(5), 495-517. doi: 10.1002/(sici)1099-1255(199609)11:5<495::aid-jae407>3.0.co;2-d

Hughes Hallett, A., \& Richter, C. (2004). A time-frequency analysis of the coherences of the US business cycle and the European business cycle (CEPR discussion paper no. 4751). London, UK: Centre for Economic Policy Research.

Jiang, C., Bahmani-Oskooee, M., \& Chang, T. (2015). Revisiting purchasing power parity in OECD. Applied Economics, 47(40), 4323-4334. doi: 10.1080/00036846.2015.1026592 


\section{FOURIER VECTOR AUTOREGRESSION}

Johansen, S. (1991). Estimation and hypothesis testing of cointegration vectors in Gaussian vector autoregressive models. Econometrica, 59(6), 15511580. doi: $10.2307 / 2938278$

Kedem, B., \& Fokianos, K. (2005). Regression models for time series analysis. New York, NY: John Wiley \& Sons. doi: 10.1002/0471266981

Korotayev, A. V., \& Tsirel, S. V. (2010). A spectral analysis of world GDP dynamics: Kondratieff waves, Kuznets swings, Juglar and Kitchin cycles in global economic development, and the 2008-2009 economic crisis. Structure and Dynamics, 4(1). Retrieved from https://escholarship.org/uc/item/9jv108xp

Kwiatkowski, D., Phillips, P. C., Schmidt, P., \& Shin, Y. (1992). Testing the null hypothesis of stationarity against the alternative of a unit root: How sure are we that economic time series have a unit root? Journal of Econometrics, 54(1-3), 159-178. doi: 10.1016/0304-4076(92)90104-y

Lack, C. (2006). Forecasting Swiss inflation using VAR models (SNB Economic Studies no. 2). Zurich, Switzerland: Swiss National Bank. Retrieved from https://www.snb.ch/en/mmr/studies/id/economic_studies_2006_02

Ludlow, J., \& Enders, W. (2000). Estimating non-linear ARMA models using Fourier coefficients. International Journal of Forecasting, 16(3), 333-347. doi: 10.1016/s0169-2070(00)00048-0

McMillen, D. P. (2001). Nonparametric employment subcenter identification. Journal of Urban Economics, 50(3), 448-473. doi: 10.1006/juec.2001.2228

McMillen, D. P., \& Dombrow, J. (2001). A flexible Fourier approach to repeat sales price indexes. Real Estate Economics, 29(2), 207-225. doi:

10.1111/1080-8620.00008

Meyer, K. (2000). Random regressions to model phenotypic variation in monthly weights of Australian beef cows. Livestock Production Science, 65(1), 19-38. doi: 10.1016/s0301-6226(99)00183-9

Newey, W. K., \& West, K. D. (1987). A simple, positive semi-definite, heteroskedasticity and autocorrelation consistent covariance matrix. Econometrica, 55(3), 703-708. doi: 10.2307/1913610

Omekara, C. O., Ekpenyong, E. J., \& Ekerete, M. P. (2013). Modeling the Nigerian inflation rates using periodogram and Fourier series analysis. $C B N$ Journal of Applied Statistics, 4(2), 51-68. Retrieved from https://www.cbn.gov.ng/Out/2014/SD/Modeling\%20the\%20Nigerian\%20Inflatio 
n\%20Rates\%20Using\%20Periodogram\%20and\%20Fourier\%20Series\%20Analys is.pdf

Phillips, P. C., \& Perron, P. (1988). Testing for a unit root in time series regression. Biometrika, 75(2), 335-346. doi: 10.1093/biomet/75.2.335

Poměnková, J., \& Kapounek, S. (2010). Business cycle development in Czech and Slovak economies. Bulletin of the Transilvania University of Braşov, Series V: Economic Sciences, 3(52), 155-66. Retrieved from http://webbut.unitbv.ro/BU2010/Series\%20V/BULETIN\%20V\%20PDF/155\%20 Pomenkova\%20Kapounek.pdf

Rayco-Solon, P., Fulford, A. J., \& Prentice, A. M. (2005). Differential effects of seasonality on preterm birth and intrauterine growth restriction in rural Africans. The American Journal of Clinical Nutrition, 81(1), 134-139. doi: 10.1093/ajen/81.1.134

Simmons, L. (1990). Time-series decomposition using the sinusoidal model. International Journal of Forecasting, 6(4), 485-495. doi: 10.1016/01692070(90)90025-7

Šmihula, D. (2009). The waves of the technological innovations of the modern age and the present crisis as the end of the wave of the informational technological revolution. Studia Politica Slovaca, 2009(1), 32-47.

Strasek, S., \& Jagric, T. (2002). Cyclical patterns in aggregate economic activity of Slovene economy. Applied Economics, 34(14), 1813-1819. doi: 10.1080/00036840210126179

Welch, I., \& Goyal, A. (2008). A comprehensive look at the empirical performance of equity premium prediction. The Review of Financial Studies, 21(4), 1455-1508. doi: 10.1093/rfs/hhm014 